\title{
A Cluster Analysis of Peer Support Training Needs for Foster Parents
}

\author{
Jason Brown (10 ${ }^{1} \cdot$ Aamena Kapasi $^{1} \cdot$ Vanessa Eyre $^{1} \cdot$ Samantha Weindels ${ }^{1}$ \\ Accepted: 29 June 2021 / Published online: 14 July 2021 \\ (c) The Author(s), under exclusive licence to Springer Science+Business Media, LLC, part of Springer Nature 2021
}

\begin{abstract}
Peer volunteers provide valuable support to foster parents. However, there has been limited research on what they consider to be valuable preparation for the role. In the present study, they were asked: "What is essential training for peer support volunteers to receive before starting?". Fifteen participants grouped 41 different responses that were analyzed using multidimensional scaling and cluster analyses. The resulting concepts included: (a) self-care, (b) effective use of self, (c) policies and procedures, (d) finding information and (e) how to address common challenges.
\end{abstract}

Keywords Concept map $\cdot$ Foster care $\cdot$ Peer support $\cdot$ Canada

\section{Highlights}

- Goals: The study's goal was to identify the training needs of foster parent peer support volunteers from the perspective of active peer support volunteers.

- Methods: Methods included multidimensional scaling and cluster analysis on 41 different responses to a focal question about "essential training for peer support volunteers."

- Results: Results of the cluster analysis yielded five themes related to self-care and use of self and policies, accessing information and problem-solving.

As public policy in the United States shifts to preventive measures to reduce the need for out-of-home placements, there is a trend toward community-based services in child protection in Canada. The majority of out-of-home placements are in foster homes. Demand for foster homes exceeds supply, and attrition is an ongoing challenge. Peer support is helpful in the retention of foster parents (Hanlon et al., 2021). Often, this support occurs between more experienced foster parents with those newer to the role. However, formalized and voluntary peer support programs have received little attention in the research literature (Miller et al., 2017). The present study aims to contribute to the literature by representing the views of experienced peer support volunteers about the necessary preservice training for new foster parent volunteers.

Foster parents tend to be motivated by a sense of responsibility to take on the challenging role. In addition,

Jason Brown

jbrow97@uwo.ca

1 Faculty of Education, Western University, London, ON, Canada they are motivated by the desire to make a difference within their extended families and communities (Gleeson et al., 2009; Smith et al., 2015). However, the needs of children in care are complex, with implications for relationships at home and functioning in school (Kinniburgh et al., 2017). In addition to school and their own families, foster parents manage expectations and interactions with child welfare systems, foster care agencies, professionals and caseworkers, birth families, neighbours, and communities. These demands can compete and compound, affecting foster parents' wellbeing and longevity (Kaasbøll et al., 2019).

Considerable research to date identifies contributors to foster parent dissatisfaction, placement instability and quitting with peer support offering a positive retention effect. The capacity to care for high-needs children is associated with foster parents' level of satisfaction (Denby et al., 1999). A recent meta-analysis of placement instability (Konijn et al., 2019) found that children's behaviour, high needs, and perceived inadequacy in foster parent skills are significant contributors. Approximately two-thirds of foster parents surveyed about their motives considered quitting (Rodger et al., 2006), and in a comparative study, foster 
parents who quit reported lower levels of support than their counterparts who continued (Rhodes et al., 2001).

Peer support is delivered in various ways but often by experienced caregivers who draw from their own practises. Helplines and chat rooms, self-help groups and friendships with other foster parents are common ways for foster parents to connect (Sinclair et al., 2004). As volunteers, the role of peer support personnel is distinguishable from the paid and often professional roles of other team members (Maclay et al., 2006). Rather than academic training and credentials, their credibility comes from personal knowledge and the ability to appreciate foster parents' daily struggles (Cohen \& Canan, 2006; MacGregor et al., 2006). Those who navigate the system and find success provide helpful examples, resources and model resilience to other foster parents (Cooley et al., 2017). They also tend to answer honestly and candidly about what works (Cooley \& Petren, 2011).

Foster parents typically receive preservice training. After placement, the foster care agency often delivers continued training informed by caregivers' and children's needs. A substantial literature on the training needs of foster parents exists. However, there is little attention on training foster parents to become peer support volunteers. This section reviews the literature on training caregivers in foster care focusing on content, skills and resources.

Regarding content knowledge, Miller et al. (2017) described a need for training on behaviour management and cultural competence for which there are well-established pieces of literature (e.g., Solomon et al., 2017; Sanchirico \& Jablonka, 2000). Also, knowledge of foster parents' role within the out-of-home placement and child protection systems specifically helps foster parents (Buehler et al., 2006). The complexity of the systems, their idiosyncrasies, and contradictions between intentions and practices contribute to a range of experiences that peer support volunteers will have. These challenges shape foster parents' information needs (Cooley et al., 2017) and should, therefore, be incorporated into their training to become peer support volunteers.

In addition to content knowledge, caregiver training has included specialized skills. For example, training with foster parents concerning child behavioural issues has included their stress tolerance and reframing abilities (Garza et al., 2007). Training also includes skills that focus on implementing reinforcement, behavioural monitoring, de-escalation, and conflict resolution (Price et al., 2008; Dorsey et al., 2008). Additionally, assertiveness skills for caregivers to identify and express their own needs in a caregiving capacity within the family and in a service provider role within the system help access supports and resources that need to be approved or provided (Murray et al., 2011). Finally, problem-solving steps and processes are essential to navigate challenges within the family and system, to prevent and manage issues before developing into more severe problems (Taylor \& McQuillan, 2014).

Training may also include specific resources. Peer support volunteers need to have a level of familiarity with established programs and the specific requirements to access them, whether they be online, within the agency or broader community (Maaskant et al., 2016). In addition to resources for their children, caregivers also benefit from resources for their self-care in general, to manage the stress of their role, as well as obtaining the support necessary to manage unexpected new and everyday personal or family stressors (e.g., care of a relative, bereavement, job change) (Farmer et al., 2005). Additional resources include access to policies and procedures, education or upgrading programs, advocacy services, local professionals, such as physicians and dentists who are receptive and accommodating (Bryan et al., 2010). While substantial literature exists on foster parent training, relatively little research exists on the training needs of peer support volunteers for foster parents.

In the present study, peer support volunteers work within a community agency providing service to foster parents in a central Canadian province. The province includes four child protection authorities to address the longstanding overrepresentation of Indigenous children and families in the child protection system. The authorities include Northern First Nations and Southern First Nations, with Metis and General Authorities covering the entire province. The host agency is a community-based not-for-profit agency providing information and support for all foster parents. The peer support program is distance-based (and was pre-COVID), relying on telephone, email, and video contact with an experienced volunteer to foster parents who call a toll-free telephone number or send an email to a specific address for support. While it is to be available 7 days a week and $24 \mathrm{~h}$ a day, response times vary depending on staffing.

Concept mapping is an approach to the collection and analysis of qualitative data. What distinguishes it from other qualitative methods is statistical procedures that produce a visual representation of participants' perceptions. In concept mapping, participants are involved in both the generation of ideas and their analysis. For example, the method has been used in child welfare to explore public perceptions of citizen review mechanisms (Miller \& Jones, 2015) and knowledge of kinship care (Lianekhammy et al., 2019). In foster care, caregiver needs (Miller \& Donohue-Dioh, 2017; Van Holen et al., 2019a) and successes (Van Holen et al., 2019b) are the subjects of previous concept mapping studies. Peer support program research includes conceptualization (Miller et al., 2017a) and gender matching (Miller et al., 2017b).

There are not enough foster homes to meet demand. Peer support prevents foster parent attrition. Formal programs that connect experienced foster parents with others who need 
support are promising but not well studied. In the present study, the focus is on one aspect of peer support program development. The goal of the study is to identify essential qualities of training needed to prepare peer support volunteers. Foster parents volunteering on a helpline to support other foster parents in a central Canadian jurisdiction responded to the question: "What is essential training for peer support volunteers to receive before starting?" Responses were analyzed using the concept mapping method.

\section{Method}

\section{Procedure}

The present study was part of an evaluation of programs in a large community development foster care agency. The agency does not determine who becomes or remains a licensed foster parent. Instead, the agency's purpose is to support and advocate for all licensed foster parents in the jurisdiction. One component of the evaluation was to explore the qualities of practical peer support and the training needs as perceived by volunteers themselves. As per the approved university ethics protocol ("Foster Parent Peer Support," \#105283, 2015), telephone numbers for program volunteers were provided to the researchers. Participants were informed that their responses would be anonymized and that they could choose to decline or withdraw participation without consequence as only aggregate data would be provided to the agency.

Members of the research team ( $\mathrm{S} \& \mathrm{~V}$ ) contacted potential participants by telephone. Following their verbal consent, the same authors ( $\&$ V) interviewed closedended and open-ended questions. One of the open-ended questions was: "What is essential training for peer support volunteers to receive before starting?" The full interview took approximately $30 \mathrm{~min}$. All 15 of the peer support volunteers agreed to participate.

\section{Participants}

All participants identified as female and ranged in age from 40 to 69 years. Formal education ranged from some high school to a graduate degree. The number of years of fostering experience ranged from 3 to 21. All were fostering at the time of the interview. The number of foster children in their care ranged from 1 to 5 . All but one participant fostered with another adult caregiver in the home.

\section{Data Analysis}

Interviewers recorded all responses by hand. The first author (J) met regularly with both interviewers $(\mathrm{S} \& \mathrm{~V})$ to compare the content and quality of handwritten quotes from interviews. The authors $(\mathrm{J}, \mathrm{S} \& \mathrm{~V})$ the research team combined all responses made by all participants. First, the authors (J, S \& V) independently reviewed the list of responses. As per the Concept Mapping method (e.g., DeVries et al., 2014), each flagged any response that appeared redundant or unclear. Next, the authors reviewed all responses with two or more ratings of unclear or redundant. Any flagged responses remaining following those that were unclear were edited for clarity by the authors.

For example, several in the initial list of responses referred to interacting with highly emotional callers. These responses included "how to talk to someone who is really stressed," "what to do when someone is angry at me," and "how to deal with people who are really emotional and can't stop crying." The authors judged these responses to be redundant, so they selected a single response. The response that best captured the content was "how to deal with people who are really emotional and can't stop crying." In order to bring more focus to the response in a way that seemed consistent with the intent of the redundant responses, the authors edited the selected response to its final form, "how to work with people who are emotional."

Each response was on a separate slip of paper with a unique ID number. Participants received a set of all responses. An independent unstructured card sorting procedure (Rosenberg \& Kim, 1975) was used. Participants reviewed them all and grouped them conceptually "in whatever way makes sense." After mailing responses to participants, a team member followed up to ensure the material was received and was complete. A time and date were set for a follow-up telephone call by a research team member to collect the groupings by telephone.

The conceptual domain was analyzed with two distinct procedures. Multidimensional scaling placed all responses on a map, and cluster analysis then organized the responses into aggregates. The Concept System Global MAX software (Concept Systems, 2019) analyzed data and constructed the concept maps.

The purpose of multidimensional scaling is to represent a structure within particular data types involving judgements about a specific stimulus (MacCallum, 1988). Nonparametric multidimensional scaling is based on a table of similarities arranged according to similarities and differences represented by distances between these judgements. First, the data from each participant is placed in a binary similarity matrix (Trochim et al., 1994). Next, the matrices are stacked, and a total frequency for each cell is calculated. High values, those approaching the total number of participants, indicate that the responses were often grouped and imply some conceptual similarity. Low values, those closer to zero, indicate that the responses were seldom grouped, suggesting that they are not conceptually similar. 
Fig. 1 Concept Map of 41 Responses

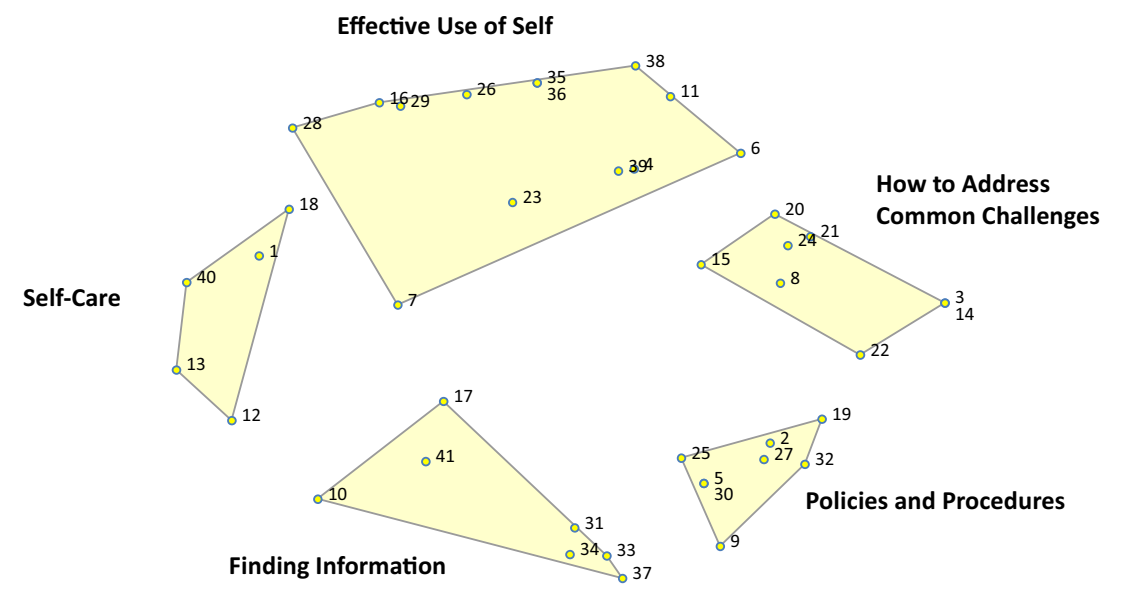

The final solution is two-dimensional, placing points for each response in a bivariate distribution plotted on an $x-y$ graph. Any number of dimensions is possible, but twodimensional solutions are more interpretable than those with more dimensions (Kruskal \& Wish, 1978). The product of this analysis was a point map. The map included all responses with distances between them, reflecting the frequency with which participants grouped them. Points near one another on the map were grouped more frequently by participants than points separated by a greater distance.

Each point has a Bridging Index. The Index is a value between 0.0 and 1.0. Smaller numbers refer to the frequency with which each was grouped with others near to it on the map. A low Index value, indicated by a value of 0.25 or less, indicated that the response was grouped only with other responses near to it on the map. A high Index value, 0.75 or higher, indicated that participants grouped the response with others in other areas of the map and those near it.

Cluster analysis is performed on the multidimensional scaling values to determine the conceptual structure. Hierarchical cluster analysis (Anderberg, 1973; Everitt, 1980) uses the coordinate values on the $\mathrm{x}-\mathrm{y}$ matrix for grouping responses on the point map into clusters that reflect conceptual similarity. Ward's (1963) minimum variance technique is one of the most effective cluster analysis methods for identifying underlying structure (Aldenderfer \& Blashfield, 1984; Blashfield \& Aldenderfer, 1988). The analysis begins with each response being treated as its own cluster, and at each step of the analysis, two clusters are combined until all responses are in a single cluster.

The cluster contents and bridging index values informed the judgement about the most appropriate number of clusters for the final map. Two of the research team members reviewed different cluster solutions and agreed that the 5cluster solution provided the greatest interpretability. While reviewing cluster maps of $12,10,8,6,5,4$ and 3 , the 12 cluster solution was highly fragmented. The ten and 8- cluster solutions were also fragmented. The 6-cluster solution provided more conceptual clarity about the underlying structure, with the clusters reflecting more content consistency within and distinctiveness between them. After reducing the clusters to 5 and then 4 , the 5 -cluster solution provided the best interpretability. The researchers determined labels for the clusters to reflect the contents of each.

\section{Results}

The resulting concept map (see Fig. 1) was constructed based on the participants' responses and groups. There were 41 different responses for the analysis (see Table 1). Fifteen participants grouped responses. A validity index, called the stress value, was calculated for the map. The value was 0.28, which was within an acceptable range (Trochim, 1994). The five concepts included: (a) self-care, (b) effective use of self, (c) policies and procedures, (d) finding information and (e) how to address common challenges.

\section{Effective Use of Self}

In this cluster, responses reflected participants' emphasis on interpersonal skills. The qualities described the need to just "be a caring person" when interacting with other foster parents. While some skills were included, the content appeared to be about "more personality than training." "Listening skills," "communication skills," and "telephone skills" are taught.

Additionally, one can engage in "empathy training" and learn about "confidentiality." However, a great deal of the preparation for the abilities reflected in this cluster develops through experience "talking to people" and knowing how to "talk to people reasonably." From experience, peer support volunteers should "know how to come alongside someone" and have the right motives. For some, these qualities matter to be able to "pay it back to other foster parents" for the help 
Table 1 Concept Brigding Indices

\begin{tabular}{|c|c|c|}
\hline \multicolumn{2}{|c|}{ Self-Care } & 0.66 \\
\hline 18. & how to deal with the public & 0.46 \\
\hline 1. & anything that can help us help parents & 0.47 \\
\hline 13. & get as much as you can & 0.65 \\
\hline 40. & vicarious trauma & 0.72 \\
\hline 12. & fetal alcohol syndrome & 1.00 \\
\hline \multicolumn{2}{|c|}{ Effective Use of Self } & 0.16 \\
\hline 36. & talking to people & 0.06 \\
\hline 35. & talk to people reasonably & 0.06 \\
\hline 26. & listening skills & 0.07 \\
\hline 29. & pay it back to other foster parents & 0.09 \\
\hline 16. & have confidence in yourself & 0.11 \\
\hline 38. & telephone skills & 0.12 \\
\hline 11. & empathy training & 0.17 \\
\hline 4. & be a caring person & 0.17 \\
\hline 39. & use your experience of being a foster parent & 0.18 \\
\hline 28. & more personality than training & 0.21 \\
\hline 6. & communication skills & 0.22 \\
\hline 23. & know how to come along side someone & 0.24 \\
\hline 7. & confidentiality & 0.37 \\
\hline \multicolumn{2}{|c|}{ Policies and Procedures } & 0.07 \\
\hline 5. & child and family act & 0.04 \\
\hline 30. & policies & 0.04 \\
\hline 9. & deal with allegations & 0.04 \\
\hline 25. & learn to use foster parent manual & 0.07 \\
\hline 27. & manuals with guidelines & 0.07 \\
\hline 2. & appeal process & 0.08 \\
\hline 32. & processes for allegations and appeals & 0.10 \\
\hline 19. & how to document when you take the calls & 0.15 \\
\hline \multicolumn{2}{|c|}{ Finding Information } & 0.16 \\
\hline 33. & required rules vs. flexible practices & 0.00 \\
\hline 37. & technical training & 0.02 \\
\hline 34. & rules and regulations from the government & 0.03 \\
\hline 31. & procedures that pertain to foster parents & 0.05 \\
\hline 41. & walked me through the steps & 0.33 \\
\hline 17. & how to access information & 0.34 \\
\hline 10. & educated me about my rights & 0.37 \\
\hline \multicolumn{2}{|c|}{ How to Address Common Challenges } & 0.23 \\
\hline 24. & know to help someone vent or actively help them & 0.19 \\
\hline 15. & hands on training & 0.19 \\
\hline 8. & conflict management & 0.19 \\
\hline 21. & how to work with people who are emotional & 0.20 \\
\hline 20. & how to work with difficult people & 0.21 \\
\hline 22. & know common questions asked & 0.26 \\
\hline 3. & attachment & 0.31 \\
\hline 14. & grief and loss & 0.31 \\
\hline
\end{tabular}

they received. Participants also described the need to "use your experience of being a foster parent" and "have confidence in yourself" for knowledge and strength.

\section{Policies and Procedures}

Responses in this cluster refer to "policies," such as the "child and family act," and when specific procedures are required. In addition to locating specific "manuals with guidelines," it was also important to "learn to use foster parent manual" to find specific information when necessary as well as their procedures such as "how to document when you make the calls." For peer support volunteers, formal knowledge of the "processes for allegations and appeals" was necessary, as well as personal experience and advice about how to handle the "appeal process" and "deal with allegations."

\section{Finding Information}

In this cluster, responses concerned foster parents' ability to identify the processes and aspects of those processes over which they had some discretion versus those that were mandated. Participants described this as knowing "required rules vs. flexible practices." In some cases, "rules and regulations from the government" were scrupulously adhered to and could be learned through "technical training." In cases where there was little to no discretion permitted, participants noted that they required knowledge of the "procedures that pertain to foster parents" and to be able to "walk me through the steps." In cases where there was some potential for discretion involved, it was necessary to learn "how to access information" and be able to "educate me about my rights."

\section{How to Address Common Challenges}

The responses in this cluster centred on ways to handle everyday challenges. Peer support volunteers should "know common questions asked" by foster parents. Crucial and common issues included understanding "attachment" and "grief and loss" from both a child and a caregiver perspective. Peer support volunteers need to know "how to work with people who are emotional," as well as "how to work with difficult people." These occur via "hands-on training" on "conflict management." It was also important to "know to help someone vent or actively help them."

\section{Self-Care}

This cluster had the highest bridging value and was 0.40 larger than the next largest average. This result suggests that this cluster's responses were less often grouped only with other responses in the cluster. Although "how to deal with the public" and "anything that can help us help parents" had the lowest bridging values, a more typical response concerned caring for oneself as a peer support volunteer. Peer volunteers engage in self-care often (e.g., "get as much as you can"), and that they need preparation for "vicarious trauma" to recognize it in themselves. The remaining response, "fetal alcohol syndrome," had a bridging value of 1.00. A bridging value of 1.00 is the highest possible and 
indicated that this response was not only associated with the cluster in which it appears. The 1.00 value indicates that this response "bridged" (i.e., was grouped by participants) with other responses in all map areas. It is possible that participants did not view this response fitting with any of the others or that this response fits well with every other response, implying that it was either a common thread or an outlier.

\section{Discussion}

The demand for foster home placements exceeds supply. A significant contributor to the decision to continue or discontinue fostering is the adequacy of support. Programs that provide peer support have great potential to impact foster parent retention positively. In the present study, the focus is on one aspect of peer support program development. The goal is to identify essential qualities of training needed to prepare peer support volunteers from foster parent peer volunteers' perspectives.

The essential qualities of training identified by foster parent peer support volunteers reflected priorities evident in the existing literature of foster parent training more generally. Therefore, it is essential to refer to studies concerning the training of foster parents, in general, to train in peer support. The adaptation of these topics for peer support volunteers, informed by the present study results, focuses the content on what a foster parent under often substantial pressure can utilize in the moment and the short term. In addition, the findings point to the need to consider foster parents as providing care within systems and care for themselves and their families.

\section{Caring Within Systems}

Participants described the importance of training to focus on enhancing skills for interacting with others to connect with other foster parents and individuals within the foster care and child protection systems more generally. They also referred to the formal rules and requirements that foster parents are required to operate within. Role clarity for volunteers promotes appropriate boundaries in their relationships with foster parents who reach out for assistance.

Participants in the present study emphasized the personality and interpersonal style of those they would comfortably interact with. They also appreciated the individualized attention (Octoman \& McLean, 2014) and assistance with concrete advice and steps to take (Randle et al., 2017). These qualities appear in the literature (Cohen \& Canan, 2006) and facilitate candid conversations between foster parents from a place of personal humility (Cooley \& Petren, 2011). In addition, these qualities elevate perceptions of peer support volunteers by other foster parents who value their expertise and judgement (MacGregor et al., 2006) as "life-trained paraprofessionals" (Cohen \& Canan, 2006). In training, peer support volunteers may benefit from discussions about interacting and reinforcing the importance of empathetic listening.

Participants in the present study distinguished between the required and discretionary aspects of foster parents' roles. The requirements for foster parents exist within child protection and foster care mandates, their roles laid out in legislation and agency documents (Bryan et al., 2010; Buehler et al., 2006). Understanding the rules governing their role and activities is essential, but many challenges that foster parents experience are grey areas for which trainees should be prepared to provide feedback before they develop into problems (Taylor \& McQuillan, 2014). Notably, a trusted peer can highlight the most salient aspects and offer clarity and reassurance (Cooley et al., 2017). In training, peer support volunteers would benefit from knowing where to locate documentation that speaks to foster parents' roles and how that information can be used in problem-solving.

Another vital training topic is the role of the volunteer. Peer support volunteers must clarify from the start what is confidential, what they are required to share with whom, and what they document (Murray, 2007). Foster parents often reach out with the expectation that they will speak to someone who has "been there," is arm's length from the system, and does not know them or their family. Before they tell their stories, volunteers should be explicit with foster parents about their roles and responsibilities. In training, peer support volunteers would benefit from understanding boundaries in the role, the answers to who, what and why questions about what is discussed, and an adequate self-introduction.

\section{Caring for Self and Family}

Participants described the importance of enhancing skills for self-care. Often foster parents foster to make a difference within their extended families and communities (Gleeson et al., 2009; Smith et al., 2015). Motives for helping other foster parents are to promote others' growth and development (Hart, 2007). In the present study, participants focused on the need to "pay forward" the assistance they received from more experienced foster parents when starting themselves. Participants in the present study were motivated by a belief in foster parents supporting other foster parents as a debt to repay. Supporting other foster parents is a responsibility they assume because of the support they had. These same volunteers also support other foster parents informally in ways other than formal peer support programs. It is possible that peer support volunteers could extend 
themselves to be of service to others without paying enough attention to themselves because of these motives.

Participants made distinctive responses about self-care. Participants were to stay cognizant of their health and wellbeing. In addition to the insight to recognize fluctuations and levels of stress that compromise the ability to be a good role model, resources to assist in promoting and maintaining wellness have been identified as essential aspects of training (Farmer et al., 2005). These resources are both internal (e.g., skills for relaxing, grounding) and external (e.g., community resources for personal counseling) (Maaskant et al., 2016).

In sum, there was considerable overlap between participants' experiences in the present study and the wide-ranging foster parent training literature. This overlap suggests that existing research on peer support training is generally consistent with a small, localized program. These qualitative findings also lend support and credibility to existing constructs in foster parent training for application in training for peer support volunteers. Convergence areas imply consistency across settings (i.e., interpersonal skills, policies and procedures, location of service and informational resources, a good match between peer support volunteer and foster parent, and self-care). However, there should be attention to the local needs of foster parents (i.e., attachment and loss, emotional de-escalation) and those who provide peer support.

Notably, the literature points to child behavior management as a significant training need for foster parents (Price et al., 2008; Dorsey et al., 2008). The need for behavior management implies that children in care are the challenge that foster parents are reaching out to peer support for assistance with. While this is consistent with prior studies (e.g., Konijn et al., 2019), foster parents in the present study were concerned about their interactions with agencies within the regulatory systems that monitor their efforts. This may be related to the number of changes that have developed over the past several years with the restructuring of child welfare and foster care in this jurisdiction.

\section{Limitations}

There are several limitations to the present study. First, it is unknown to what extent the participants in this program reflect the training needs of foster parent peer support volunteers relative to others in other jurisdictions. Second, while inclusive of all peer support volunteers in a specific program, the sample size is modest. Third, the method included participants in the generation of ideas and analysis of those ideas. In the absence of audio recordings of the interviews, it is not possible to validate the responses relative to original transcripts.

\section{Conclusions}

The findings of this study do point to implications for policy, practice and future research. Regarding policy, it is essential to note that peer support volunteers are acting in an unpaid capacity. While there appear to be benefits for other foster parents, volunteers' time, energy, and expertise are not without cost. In addition to program infrastructure and paid administrative staff, the volunteers themselves are making significant contributions for which they are not compensated. Sustainability seems possible given the motives of peer supporters to repay the "free" assistance they received from other foster parents. However, in the absence of compensation, the cost is borne primarily by foster parents who are already overworked and underpaid. Therefore, these initiatives should be resourced based on a calculation of the value of service provided, including the costs of this valuable service provided by foster parents.

Concerning practice, findings of the study suggest that foster parents who provide peer support also benefit from training and support for themselves. It is essential to remain cognizant of the value these volunteers, assumed to be among the more experienced and knowledgeable of foster parents, are contributing to the program, agency and system by promoting good relationships with children in care, reducing the demand on paid staff and assisting with the retention of foster parents. The actual cost of the service provided should be borne in mind when preparing and delivering training and other forms of support to these volunteers. Agencies would do well to regard the volunteers as an essential service and treat them as such.

There are several areas of research that are underdeveloped in the area of peer support among foster parents. For example, while the program described herein is a formal program, it is unknown how it compares to the informal support that many foster parents provide to other foster parents. Large scale studies of peer support-both formal and informal-would be very helpful to identify who is doing it, what kinds of support are being offered and how much support is being offered. In addition, it would be important to explore similarities and differences in smaller versus larger communities, as well as who benefits most from peer support and how those benefits translate into standard foster care metrics on placement stability and foster parent retention.

Acknowledgements The authors would like to acknowledge the financial support of this research through a grant from the Social Sciences and Humanities Research Council of Canada. We would also like to thank the Manitoba Foster Family Network group for their assistance and participants for their contributions to this study. 


\section{Compliance with Ethical Standards}

Conflict of Interest The authors declare no competing interests.

Ethical Approval Ethical review and approval were provided by the corresponding author's institution.

Informed Consent Informed consent was provided by all participants.

Publisher's note Springer Nature remains neutral with regard to jurisdictional claims in published maps and institutional affiliations.

Open Access This article is licensed under a Creative Commons Attribution 4.0 International License, which permits use, sharing, adaptation, distribution and reproduction in any medium or format, as long as you give appropriate credit to the original author(s) and the source, provide a link to the Creative Commons license, and indicate if changes were made. The images or other third party material in this article are included in the article's Creative Commons license, unless indicated otherwise in a credit line to the material. If material is not included in the article's Creative Commons license and your intended use is not permitted by statutory regulation or exceeds the permitted use, you will need to obtain permission directly from the copyright holder. To view a copy of this license, visit http://creativecommons. org/licenses/by/4.0/.

\section{References}

Aldenderfer, M. S., \& Blashfield, R. K. (1984). Cluster Analysis. Beverly Hills: Sage.

Anderberg, M. (1973). Cluster analysis for applications. New York, NY: Academic Press.

Blashfield, R. K., \& Aldenderfer, M. S. (1988). The methods and problems of cluster analysis. In Nesselroade, J. R. and Cattell, R. B. (Eds), Handbook of Multivariate Experimental Psychology (pp. 447-473). New York: Plenum.

Blythe, S. L., Jackson, D., Halcomb, E. J., \& Wilkes, L. (2012). The stigma of being a long-term foster carer. Journal of Family Nursing, 18(2), 234-260. https://doi.org/10.1177/1074840711423913.

Borgen, F. H., \& Barnett, D. C. (1987). Applying cluster analysis in counseling psychology research. Journal of Counseling Psychology, 34(4), 456-468. https://doi.org/10.1037/0022-0167.34. 4.456.

Bryan, V., Flaherty, C., \& Saunders, C. (2010). Supporting adoptive families: participant perceptions of a statewide peer mentoring and support program. Journal of Public Child Welfare, 4(1), 91-112. https://doi.org/10.1080/15548730903563178.

Buehler, C., Rhodes, K. W., Orme, J. G., \& Cuddeback, G. (2006). The potential for successful family foster care: Conceptualizing competency domains for foster parents. Child Welfare, 85(3), 523-558.

Clarke, H. (2009). Getting the support they need: findings of a survey of foster carers in the UK. [pdf] London: The Fostering Network. Available at: http://www.fostering.net/sites/www.fostering.net/ files/public/resources/reports/support_survey_240909.pdf.

Cohen, E., \& Canan, L. (2006). Closer to home: parent mentors in child welfare. Child Welfare, 85(5), 867-884. https://www.ncbi. nlm.nih.gov/pubmed/17168459.

Cole, S. A., \& Eamon, M. K. (2007). Predictors of depressive symptoms among foster caregivers. Child Abuse \& Neglect, 31 (3), 295-310. https://doi.org/10.1016/j.chiabu.2006.06.010.

Cooley, M. E., \& Petren, R. E. (2011). Foster parent perceptions of competency: implications for foster parent training. Children and
Youth Services Review, 33(10), 1968-1974. https://doi.org/10. 1016/j.childyouth.2011.05.023.

Cooley, M. E., Thompson, H. M., \& Wojciak, A. S. (2017). Risk, resilience, and complexity: experiences of foster parents. Children and Youth Services Review, 76, 35-41. https://doi.org/10. 1016/j.childyouth.2017.02.030.

Denby, R., Rindfleisch, N., \& Bean, G. (1999). Predictors of foster parents' satisfaction and intent to continue to foster. Child abuse \& neglect, 23(3), 287-303.

Dorsey, S., Farmer, E. M., Barth, R. P., Greene, K., Reid, J., \& Landsverk, J. (2008). Current status and evidence base of training for foster and treatment foster parents. Children and Youth Services Review, 30(12), 1403-1416. https://doi.org/10.1016/j. childyouth.2008.04.008.

Evans, C., Humphrey, L., Pelletier, C., \& Hudgens, S. (2017). Group concept mapping to understand the patient perspective and burden of psoriasis. SKIN The Journal of Cutaneous Medicine, 1, s16. https://doi.org/10.25251/skin.1.supp.15.

Everitt, B. (1980). Cluster analysis (2nd ed.). New York, NY: Halsted Press.

Farmer, E., Lipscombe, J., \& Moyers, S. (2005). Foster carer strain and its impact on parenting and placement outcomes for adolescents. The British Journal of Social Work, 35(2), 237-253. https://doi. org/10.1093/bjsw/bch181.

Garza, Y., Watts, R. E., \& Kinsworthy, S. (2007). Filial therapy: a process for developing strong parent-child relationships. The Family Journal, 15(3), 277-281. https://doi.org/10.1177/ 1066480707301374.

Gleeson, J. P., Wesley, J. M., Ellis, R., Seryak, C., Talley, G. W., \& Robinson, J. (2009). Becoming involved in raising a relative's child: reasons, caregiver motivations and pathways to informal kinship care. Child \& Family Social Work, 14(3), 300-310. https://doi.org/10.1111/j.1365-2206.2008.00596.x.

Hanlon, R., Simon, J., Day, A., Vanderwill, L., Kim, J., \& Dallimore, E. (2021). Systematic review of factors affecting foster parent retention. Families in Society, https://doi.org/10.1177/1044389420970034.

Hargett, C. W., Doty, J. P., Hauck, J. N., Webb, A. M., Cook, S. H., Tsipis, N. E., Neumann, J. A., Andolsek, K. M., \& Taylor, D. C. (2017). Developing a model for effective leadership in healthcare: a concept mapping approach. Journal of Healthcare Leadership, 9, 69-78. https://doi.org/10.2147/JHL.S141664.

Hart, A., Blincow, D., \& Thomas, H. (2007). Resilient therapy: Working with children and families. New York: Routledge.

Van Holen, F., Geys, L., West, D., Gypen, L., \& Vanderfaeillie, J. (2019a). Characteristics of successful foster families according to Flemish foster care workers. Children and Youth Services Review, 107, 104519. https://doi.org/10.1016/j.childyouth.2019. 104519.

Van Holen, F., Trogh, L., West, D., Meys, N., \& Vanderfaeillie, J. (2019b). Concept mapping the needs of Flemish nonkinship foster parents who care for unaccompanied refugee minors. Children and Youth Services Review, 96, 84-92. https://doi.org/ 10.1016/j.childyouth.2018.11.043.

Kaasbøll, J., Lassemo, E., Paulsen, V., Melby, L., \& Osborg, S. O. (2019). Foster parents' needs, perceptions and satisfaction with foster parent training: A systematic literature review. Children and Youth Services Review, 101, 33-41. https://doi.org/10.1016/j. childyouth.2019.03.041.

Kinniburgh, K. J., Blaustein, M., Spinazzola, J., \& van der Kolk, B. A. (2017). Attachment, self-regulation, and competency: A comprehensive intervention framework for children with complex trauma. Psychiatric Annals, 35(5), 424-430. https://doi.org/10. 3928/00485713-20050501-08.

Konijn, C., Admiraal, S., Baart, J., van Rooij, F., Stams, G.-J., Colonnesi, C., Lindauer, R., \& Assink, M. (2019). Foster care placement instability: a meta-analytic review. Children and Youth 
Services Review, 96, 483-499. https://doi.org/10.1016/j. childyouth.2018.12.002.

Kruskal, J. B., \& Wish, M. H. (1978). Multidimensional Scaling. New York: Sage.

Lianekhammy, J., Miller, J. J., Koh, E., \& Kurzynske, J. S. (2019). Exploring the public's knowledge about kinship care: a crosssectional study. Journal of Public Child Welfare, 13(5), 578-595. https://doi.org/10.1080/15548732.2019.1596194.

Lorr, M. (1983). Cluster Analysis for Social Scientists. San Francisco: Jossey-Bass.

Maaskant, A. M., van Rooij, F. B., Overbeek, G. J., Oort, F. J., \& Hermanns, J. M. A. (2016). Parent training in foster families with children with behavior problems: follow-up results from a randomized controlled trial. Children and Youth Services Review, 70, 84-94. https://doi.org/10.1016/j.childyouth.2016.09.005.

MacCallum, R. (1988). Multidimensional scaling. In Nesselroade, J. R. and Raymond, B. Cattell (Eds), Handbook of Multivariate Experimental Psychology (pp. 421-445). New York, NY: Plenum.

MacGregor, T. E., Rodger, S., Cummings, A. L. \& Leschied, A. W. (2006). The needs of foster parents : A qualitative study of motivation, support, and retention. Qualitative Social Work, 5(3), 351-368. https://doi.org/10.1177/1473325006067365.

Maclay, F., Bunce, M., \& Purves, D. (2006). Surviving the system as a foster carer. Adoption \& Fostering, 30(1), 29-38. https://doi.org/ 10.1177/030857590603000105.

Miller, J., Benner, K., Pope, N., Dumas, T., Damron, L. J., Segress, M., Slone, M., Thrasher, S., \& Niu, C. (2017). Conceptualizing effective foster parent mentor programs: a participatory planning process. Children and Youth Services Review, 73, 411-418. https://doi.org/10.1016/j.childyouth.2017.01.004.

Miller, J., Benner, K., Thrasher, S., Pope, N., Dumas, T., Damron, L. J., Segress, M., \& Niu, C. (2017). Planning a mentorship initiative for foster parents: does gender matter? Evaluation and Program Planning, 64, 78-84. https://doi.org/10.1016/j.eva lprogplan.2017.05.009.

Miller, J. J., Benner, K., Pope, N., Dumas, T., Damron, L. J., Segress, M., Slone, M., Thrasher, S., \& Niu, C. (2017a). Conceptualizing effective foster parent mentor programs: a participatory planning process. Children and Youth Services Review, 73, 411-418. https://doi.org/10.1016/j.childyouth.2017.01.004.

Miller, J. J., Benner, K., Thrasher, S., Pope, N., Dumas, T., Damron, L. J., Segress, M., \& Niu, C. (2017b). Planning a mentorship initiative for foster parents: does gender matter? Evaluation and Program Planning, 64, 78-84. https://doi.org/10.1016/j.eva lprogplan.2017.05.009.

Miller, J. J., \& Donohue-Dioh, J. (2017). Mapping the needs of kinship providers: a mixed-method examination. GrandFamilies: The Contemporary Journal of Research, Practice and Policy, 4(2), 4.

Miller, J. J., Donohue-Dioh, J., \& Brown, A. (2018). Using concept mapping to develop a statewide kinship care coalition: a case study. Journal of Community Practice, 26(2), 162-183. https:// doi.org/10.1080/10705422.2018.1449155.

Miller, J. J., Duron, J. F., Donohue-Dioh, J., \& Geiger, J. M. (2018). Conceptualizing effective legal representation for foster youth: a group concept mapping study. Children and Youth Services Review, 91, 271-278. https://doi.org/10.1016/j.childyouth.2018.06.031.

Miller, J. J., \& Jones, B. (2015). Using concept mapping as a planning tool: child welfare citizen review panels. Evaluation and Program Planning, 53, 99-106. https://doi.org/10.1016/j.evalprogpla n.2015.08.001.

Murray, L. (2007). Foster and kinship caregiver perceptions of support and training in Canterbury, New Zealand. M. Ed. University of Canterbury, New Zealand. Retrieved from: http://ir.canterbury.ac. nz/bitstream/10092/1061/2/thesis_fulltext.pdf.txt.
Murray, L., Tarren-Sweeney, M., \& France, K. (2011). Foster carer perceptions of support and training in the context of high burden of care. Child \& Family Social Work, 16(2), 149-158. https://doi. org/10.1111/j.1365-2206.2010.00722.x.

Newstone, S. (2008). Foster carer peer mentoring: good practice guidelines for establishing and running a peer mentoring scheme. [pdf] London: The Fostering Network. Retrieved from: http://www.consultingmatters.co.uk/html/peer_mentoring.pdf.

Northwest Institute for Children and Families (2007). Mockingbird Family Model project evaluation. [pdf] Retrieved from: http://www.mockingbirdsociety.org/images/stories/docs/MFM/ nwicf_2007-5_report.pdf.

Octoman, O., \& McLean, S. (2014). Challenging behaviour in foster care: what supports do foster carers want? Adoption \& Fostering, 38(2), 149-158. https://doi.org/10.1177/0308575914532404.

Price, J. M., Chamberlain, P., Landsverk, J., Reid, J. B., Leve, L. D., \& Laurent, H. (2008). Effects of a foster parent training intervention on placement changes of children in foster care. Child Maltreatment, 13(1), 64-75. https://doi.org/10.1177/1077559507310612.

Randle, M., Ernst, D., Leisch, F., \& Dolnicar, S. (2016). What makes foster carers think about quitting? Recommendations for improved retention of foster carers. Child \& Family Social Work, 22(3), 1175-1186. https://doi.org/10.1111/cfs.12334.

Randle, M., Ernst, D., Leisch, F., \& Dolnicar, S. (2017). What makes foster carers think about quitting? Recommendations for improved retention of foster carers. Child \& Family Social Work, 22(3), 1175-1186.

Rhodes, Kathryn, W, Orme, John, G, \& Buehler, C. (2001). A comparison of family foster parents who quit, consider quitting, and plan to continue fostering. Social Service Review, 75(1), 84-114. https://doi.org/10.1086/591883.

Rodger, S., Cummings, A., \& Leschied, A. W. (2006). Who is caring for our most vulnerable children? The motivation to foster in child welfare. Child Abuse \& Neglect, 30(10), 1129-1142. https://doi.org/10.1016/j.chiabu.2006.04.005.

Rosenberg, S., \& Park Kim, M. (1975). The method of sorting as a data-gathering procedure in multivariate research. Multivariate Behavioral Research, 10(4), 489-502. https://doi.org/10.1207/ s15327906mbr1004_7.

Sanchirico, A., \& Jablonka, K. (2000). Keeping foster children connected to their biological parents: the impact of foster parent training and support. Child and Adolescent Social Work Journal, 17(3), 185-203. https://doi.org/10.1023/a:1007583813448.

Sinclair, I., Gibbs, I. and Wilson, K. (2004). Foster carers: why they stay and why they leave. London, UK: Jessica Kingsley.

Smith, J., Rodger, S., Brown, J., Pickel, L., den Dunnen, W., \& Leschied, A. (2015). Comparing the experiences and withdrawal considerations of treatment and regular foster care parents: The Canadian perspective. International Journal of Child, Youth and Family Studies, 6(1), 93-110. https://doi.org/10.18357/ijcyfs.61201513480.

Solomon, D. T., Niec, L. N., \& Schoonover, C. E. (2017). The impact of foster parent training on parenting skills and child disruptive behavior. Child Maltreatment, 22(1), 3-13. https://doi.org/10. 1177/1077559516679514.

Taylor, B. J., \& McQuillan, K. (2014). Perspectives of foster parents and social workers on foster placement disruption. Child Care in Practice, 20(2), 232-249. https://doi.org/10.1080/13575279. 2013.859567.

Trochim, W. M. K., Cook, J. A., \& Setze, R. J. (1994). Using concept mapping to develop a conceptual framework of staff's views of a supported employment program for individuals with severe mental illness. Journal of Consulting and Clinical Psychology, 62 (4), 766-775. https://doi.org/10.1037/0022-006x.62.4.766.

De Vries, G., Hees, H. L., Koeter, M. W. J., Lagerveld, S. E., \& Schene, A. H. (2014). Perceived impeding factors for return-towork after long-term sickness absence due to major depressive 
disorder: a concept mapping approach. PLOS ONE, 9(1), e85038. https://doi.org/10.1371/journal.pone.0085038.

Ward, J. H. (1963). Hierarchical grouping to optimize an objective function. Journal of the American Statistical Association, 58, 236-244. https://doi.org/10.1080/01621459.1963.10500845.
Whenan, R., Oxlad, M., \& Lushington, K. (2009). Factors associated with foster carer wellbeing, satisfaction and intention to continue providing out-of-home care. Children and Youth Services Review, 31(7), 752-760. https://doi.org/10.1016/j.childyouth.2009.02. 001. 